\title{
PENILAIAN PEMANFAATAN TEKNOLOGI E-BUSINESS PADA INDUSTRI UMKM
}

\author{
Noerlina; Siti Elda Hiererra \\ Information Systems Department, School of Information Systems, Binus University \\ Jl. K.H. Syahdan No. 9, Palmerah, Jakarta Barat 11480 \\ nurlina@binus.edu; hiererra@binus.edu
}

\begin{abstract}
Contribution of MSMEs (micro, small and medium enterprises) in the economy is significant enough. It indicates the importance of support for MSMEs to maintain and double the capacity their businesses. In conducting its business, $76 \%$ of respondents already use the Internet (e-business) but still not optimally because the average does not have a website as a forum for the promotion and selling activity. Total mean score of 4.2 in adoption of innovations indicates that it has been realized, done, evaluated and adopted as a whole. Therefore, it is necessary to perform an assessment on what extent of e-business application that has been done by reviewing the readiness of MSME industries and the aspects of the utilization of information and communication technology (ICT) by MSMEs particularly of those located in Jabodetabek. The purpose of this assessment is to get an overview, status and position of the support of implementation of e-business owned and how the adoption process of e-business application can run in Jabodetabek. With the assessment of e-business technology use, we expect the planning, implementation and control of programs as well as the implementation of e-business can be conducted more directedly and controlled.
\end{abstract}

Keywords: assessment, use of internet, e-busines, MSME

\begin{abstract}
ABSTRAK
Kontribusi UMKM (usaha mikro, kecil dan menengah) dalam perekonomian yang cukup signifikan mengindikasikan pentingnya dukungan terhadap UMKM untuk mempertahankan dan melipatgandakan kapasitas bisnis UMKM. Dalam menjalankan usahanya, 76\% responden sudah memanfaatkan internet (ebusiness) tapi masih belum secara maksimal karena rata-rata masih belum mempunyai website sebagai wadah promosi maupun kegiatan jual beli. Total skor rata-rata untuk UMKM sebesar 4.2 menunjukkan bahwa adopsi terhadap inovasi di dalam pemahaman layanan internet sudah disadari, sudah dilakukan, sudah dievaluasi dan sudah di adopsi secara menyeluruh. Oleh karena itu, perlu dilakukan suatu penilaian sejauh mana penerapan ebusiness yang sudah dilakukan di dalam industri UMKM dengan meninjau aspek kesiapan dari industri yang bersangkutan dan aspek pemanfaatan teknologi informasi dan komunikasi (TIK) oleh UMKM khususnya di Jabodetabek. Tujuan dari penilaian ini untuk mendapatkan gambaran, status dan posisi daya dukung terhadap penerapan e-Business yang dimiliki dan bagaimana proses adopsi penerapan e-business dapat berjalan di wilayah Jabodetabek. Dengan adanya penilaian pemanfaatan teknologi e-business ini diharapkan proses perencanaan, pelaksanaan dan pengendalian program serta kegiatan penerapan e-business dapat dilakukan dengan lebih terarah dan terkendali.
\end{abstract}

Kata kunci: penilaian, pemanfaatan internet, e-busines, UMKM 


\section{PENDAHULUAN}

Magnusson (2011) menyatakan bahwa "SMEs (Small and Medium-sized Enterprises) nowadays have to deal with the highly complex situation of global competition, fast technology development and extensive business networking. Because of their importance for the economy, it is essential that SMEs embrace new technology and adapt to societal changes such as the increasing use of eCommerce". Jika diterjemahkan, UKM (Usaha Kecil dan Menengah) saat ini terkait dengan situasi persaingan global yang sangat kompleks, pesatnya perkembangan teknologi dan jaringan bisnis yang luas. Karena pentingnya UKM bagi perekonomian, penting bagi UKM untuk merangkul teknologi baru dan beradaptasi dengan perubahan sosial seperti eCommerce yang penggunaannya semakin meningkat.

Kontribusi UMKM dalam perekonomian yang cukup signifikan memberikan indikasi pentingnya dukungan terhadapa UMKM untuk mempertahankan dan melipatgandakan kapasitas bisnis UMKM. Oleh karena itu, perlu dilakukan suatu penilaian sejauh mana penerapan e-business sudah dilakukan di dalam industry UMKM ini dengan meninjau aspek kesiapan dari industri yang bersangkutan dan aspek pemanfaatan TIK oleh UMKM untuk mendukung operasional bisnis.

Hasil penelitian pendahuluan yang dilakukan menunjukkan bahwa sebagian besar entrepreneur sudah memulai usaha sendiri ketika berusia dibawah 35 tahun (60\% dari total responden 76), dan berjenis kelamin wanita dengan alasan menjadi entrepreneur karena kebebasan waktu yang dimiliki sebesar 58\% serta berpendidikan rata-rata SLTA atau sederajat. $76 \%$ responden dalam menjalankan usahanya sudah memanfaatkan internet (E-business) tetapi masih belum secara maksimal (Gambar 1). Hal ini dikarenakan rata-rata masih belum mempunyai website sebagai wadah promosi maupun kegiatan jual beli.

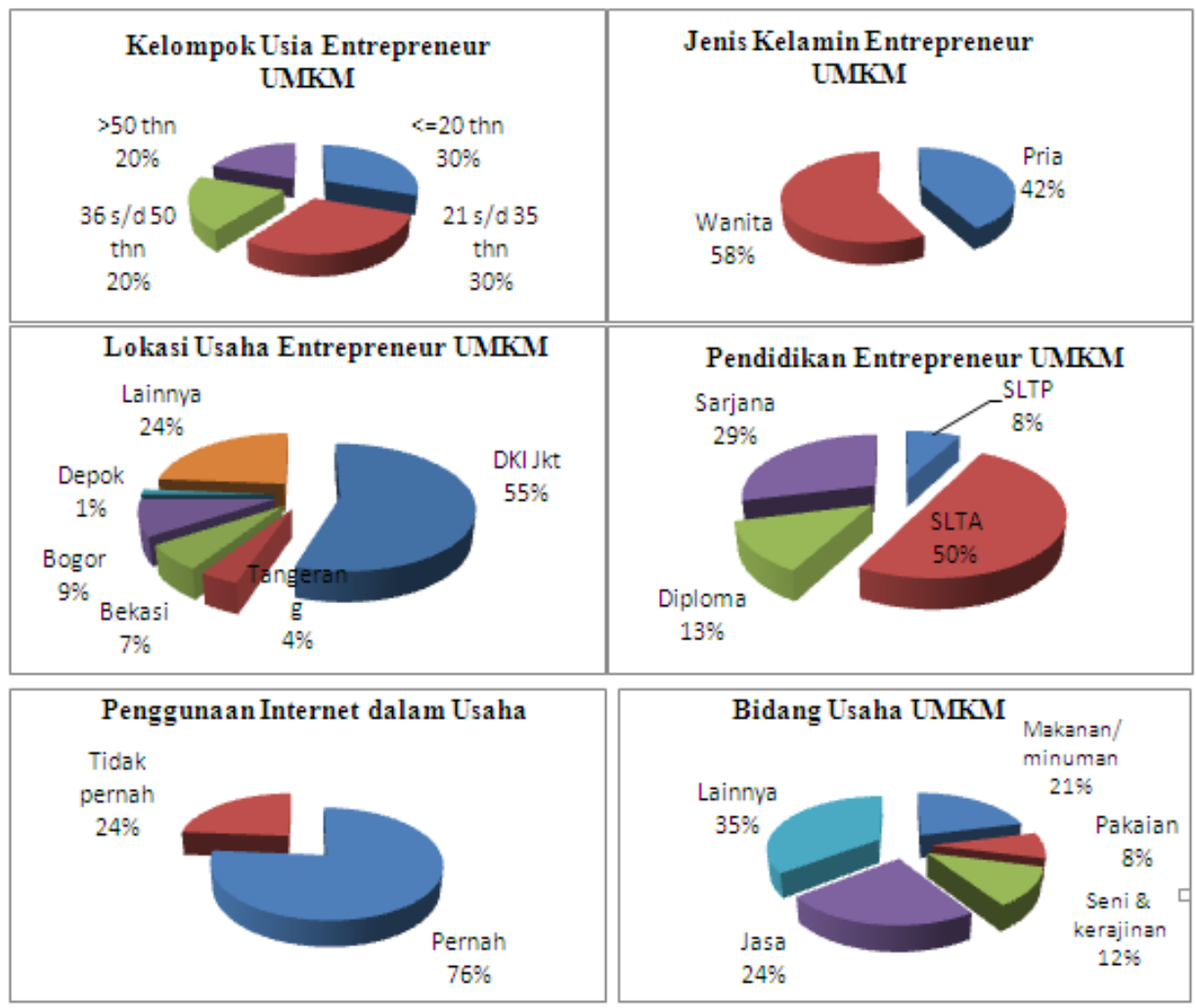

Gambar 1 Hasil survei responden 
Oleh karena itu, perlu dilakukan suatu penilaian sejauh mana penerapan e-business sudah dilakukan di dalam industry UMKM ini dengan meninjau aspek kesiapan dari industri yang bersangkutan dan aspek pemanfaatan TIK untuk mendukung operasional bisnis. Penilaian e-Business diharapkan dapat mendorong UMKM untuk melakukan perencanaan dan pelaksanaan program pemanfaatan TIK dalam e-Business untuk peningkatan kemampuan masyarakat dalam memanfaatkan e-Business sehingga memberikan kontribusi yang signifikan untuk pertumbuhan ekonomi di masingmasing wilayah.

Penelitian ini bertujuan untuk melakukan penilaian atas pemanfaatan teknologi e-business pada industri UMKM di Jabodetabek untuk mendapatkan gambaran, status dan posisi sejauh mana daya dukung terhadap penerapan e-Business yang dimiliki dan bagaimana proses adopsi penerapan eBusiness dapat berjalan di wilayah tersebut. Dengan adanya penilaian pemanfaatan teknologi EBusiness ini diharapkan proses perencanaan, pelaksanaan dan pengendalian program dan kegiatan penerapan e-Business dapat dilakukan dengan lebih terarah dan terkendali.

\section{METODE}

Metode penilaian pemanfaatan teknologi e-business yang akan digunakan pada kegiatan penelitian ini adalah seperti yang terlihat pada Gambar 1 di bawah ini:

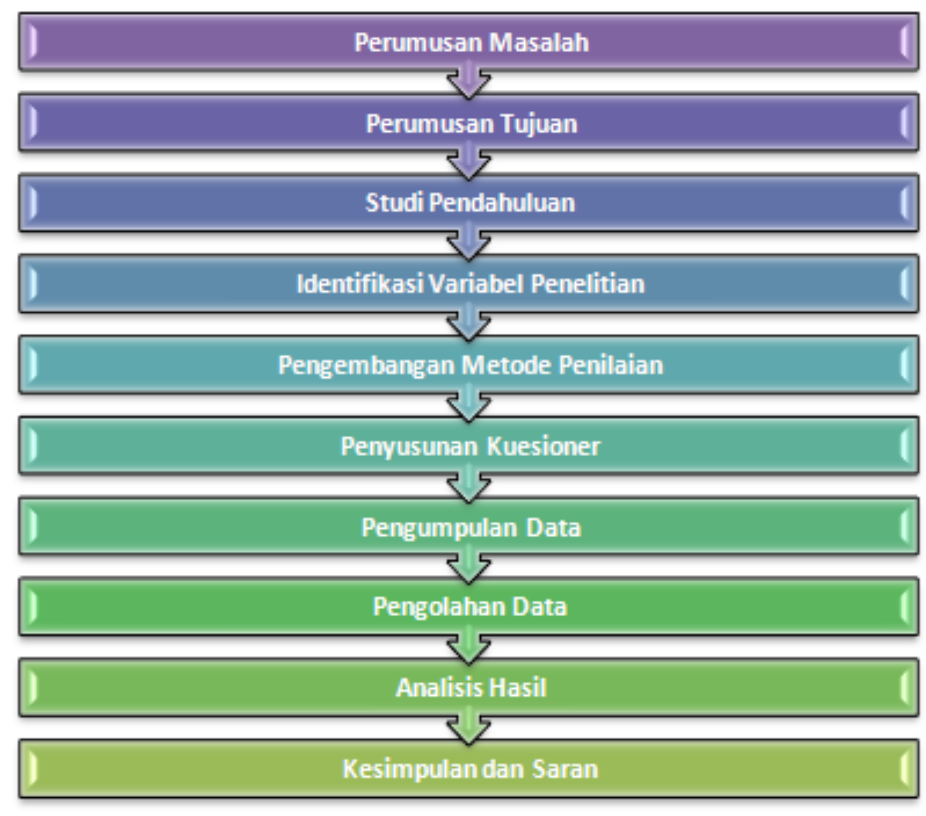

Gambar 1 Langkah-langkah dalam metode penelitian

\section{Tinjauan Pustaka}

\section{Konsep E-Business}

Teknologi Informasi dan Komunikasi adalah komponen yang sangat penting dalam proses bisnis, baik barang maupun jasa dalam meraih keunggulan kompetitif. Teknologi Informasi dan Komunikasi mengubah cara orang bekerja (the way people work) sekaligus mengubah cara perusahaan 
bersaing (the way business compete). Dukungan Teknologi Informasi dan Komunikasi mengembangkan cara baru dalam bertransaksi (e-commerce).

Perkembangan fungsi e-commerce mendorong munculnya $e$-business. E-business merupakan praktik pengelolaan proses bisnis utama seperti perancangan produk, pengelolaan pasokan bahan baku, penjualan, dan penyediaan layanan melalui penggunaan teknologi informasi/komunikasi, dan/atau data yang telah terkomputerisasi (Alter, 2002). Dengan kata lain, e-business dapat didefinisikan sebagai pemanfaatan Teknologi Informasi dan Komunikasi dalam mendukung semua kegiatan bisnis.

Faktor-faktor yang mempengaruhi kesuksesan E-Business di antaranya promosi yang dilakukan tepat oleh perusahaan, budaya perusahaan dan pengetahuan serta kemampuan sumber daya perusahaan dalam hal perkembangan TIK (Teknologi Informasi dan Komunikasi) e-business itu sendiri (Bentahar dan Namaci, 2012).

E-Business semakin marak dan para penentu kebijakan memahami bahwa Teknologi Informasi tidak dapat bertindak sendirian. Ada beberapa aspek penting yang harus dikondisikan juga seperti strategi bisnis, perencanaan, pengorganisasian, keuangan, dan manajemen resiko. Aspek aspek yang perlu dikondisikan tersebut merupakan aspek yang sangat penting agar E-Business berkembang secara positif.

Beberapa pandangan kritis mengenai E-Business yang dituangkan oleh Deise (2000), pandangan tersebut adalah sebagai berikut: (1) e-business adalah suatu keharusan. Teknologi akan terus berubah, e-business akan terus tampil dan lebih eksis di masa mendatang di berbagai bidang. $E$ business akan menjadi standar operasi tidak hanya sebatas layanan finansial, percetakan dan retail. Visi para eksekutif akan menjadi titik kritis keberhasilan penerapan e-business; (2) e-business merupakan fondasi setiap kegiatan bisnis, baik itu berkaitan dengan strategi bisnis maupun kegiatan proses eksekusi; (3) waktu bertindak untuk antisipasi penerapan E-Business adalah Sekarang. Dengan bertindak mengantisipasi penerapan e-business secara cepat, akan didapatkan keuntungan penggunaan waktu yang lebih cepat dan mendapatkan uang lebih banyak.

\section{E-Business dan UMKM}

Pada kasus implementasi e-business di Indonesia khususnya UMKM memiliki tantangan yang menarik karena level pemahaman terhadap teknologi informasi dan komunikasi yang berbeda pada setiap wilayah di Indonesia.

Dari beberapa isu sebagaimana disampaikan diatas, penerapan e-business pada sektor UMKM menjadi isu yang cukup penting. Termasuk dalam hal ini upaya penerapan e-business yang didorong oleh pemerintah Indonesia dalam mendorong pemanfaatan e- business oleh UMKM. Kendala yang dihadapi oleh UMKM dalam menerapkan e-business di antaranya adalah pemahaman tentang ebusiness itu sendiri yang belum dipahami oleh sebagian besar UMKM di Indonesia.

\section{Manfaat E-Business Bagi Perkembangan Bisnis UMKM}

Tujuan dari setiap bisnis adalah memaksimalkan pendapatan dan meminimalkan pengeluaran sehingga total pendapatan semakin besar. Setiap pelaku bisnis akan menimbang apakah dengan melakukan implementasi e-business dapat memberikan pencapaian tujuan organisasi bisnis.

\section{Implementasi Model E-Business}

Proses pengembangan e-business adalah proses yang berjalan secara bertahap. Hal ini berlaku tidak hanya bagi UMKM. Ketika suatu organisasi menerapkan e-business maka yang sangat perlu 
dilakukan adalah menjaga dampak perubahan yang terjadi dalam menerapkan e-business tersebut. Model implementasi e-business dapat dikelompokkan dalam Internal Implementation Model (IIM) dan Looping Step Models (LSM).

Model IIM membantu UMKM dalam menerapkan strategi bisnis dan pengambilan keputusan perusahaan dalam organisasi. Model ini memberikan gabungan antara: (1) decision support tools: long term strategy and "go/no go" decisions; (2) management support tool: management skills and knowledge base; (3) operational support tool: implementation activities to deliver the project.

Setiap tool tahapan diatas memberikan layanan yang membantu pada setiap tahapan manajemen dalam UMKM untuk menyelesaikan setiap permasalahan dalam setiap level bisnis. Level tersebut di antaranya level strategis, level manajemen, dan level operasi. IIM membantu UMKM yang memiliki minat untuk menerapkan $e$-business dengan membuat keputusan yang tepat pada setiap level organisasi. Proses yang berulang dalam internal organisasi selanjutnya dilakukan secara berulang untuk mencapai tingkatan yang lebih baik. Model ini disebut dengan Looping Step Model (LSM).

LSM adalah prosses yang terus menerus dalam menerapkan IIM, dimana dalam setiap tahapan merupakan proses IIM dan secara berkelanjutan memberikan umpan balik informasi untuk mencapai level yang lebih baik. Sampai pada tahapan tertentu dapat memberikan keberhasilan bagi organisasi.

Pada umumnya UMKM di Indonesia inisiatif datang dari pimpinan tertinggi yang umumnya juga merangkap sebagai pemilik. Dengan demikian visi dari pemilik UMKM menjadi sangat penting. UMKM yang menerapkan e-business harus mempertimbangkan bagaimana mengelola perubahan yang terjadi mencakup manusia, proses, informasi, dan teknologi. Penilaian e-business dapat membantu UMKM untuk mengukur sejauh mana menerapkan e-business dalam organisasi bisnisnya. Karena implementasi e-business dipengaruhi tidak hanya oleh UMKM tetapi faktor luar dalam hal ini pemerintah maka diperlukan pemeringkatan yang berbeda untuk membantu baik UMKM ataupun pemerintah untuk melakukan evaluasi terhadap kesiapan implementasi e-business.

\section{Proses Adopsi E-Business}

Inovasi termasuk seluruh barang, jasa, maupun ide yang dipandang sebagai sesuatu yang baru. Munculnya berbagai aplikasi e-business merupakan sebuah inovasi dalam bidang teknologi informasi. Sebuah inovasi dapat diterima dan digunakan oleh konsumen sebagaimana tujuan inovasi itu diciptakan, melalui sebuah proses adopsi. Proses adopsi konsumen berfokus pada proses mental yang dilalui individu dari pertama mendengar tentang inovasi sampai pada adopsi final.

Adopter dari produk baru telah diobservasi bergerak melalui lima tahapan (Kotler, 2003:376), yaitu: (1) awareness (kesadaran): user menyadari inovasi tetapi kekurangan informasi tentang itu; (2) interest (ketertarikan): user dirangsang untuk mencari informasi tentang inovasi; (3) evaluation (evaluasi): user mempertimbangkan apakah akan mencoba inovasi; (4) trial (mencoba-coba): user mencoba inovasi untuk meningkatkan estimasinya tentang nilai; (5) adoption (adopsi): user memutuskan untuk menggunakan inovasi tersebut secara penuh dan teratur.

\section{HASIL DAN PEMBAHASAN}

Untuk menjawab permasalahan yang dirumuskan dalam penelitian ini, dilakukan analisis deskriptif yang meliputi langkah-langkah berikut:

Rata-rata skor untuk:

(1) Proses adopsi e-business/pemahaman layanan internet: 
$\mathrm{X}<1.85$ : awareness

1.8-2.59: interest

2.6-3.39: evaluation

3.4-4.12: trial

4.2-5.00: adoption

(2) Interpretasi terhadap manfaat e-business bagi UMKM:

$\mathrm{X}<1.85$ : sangat rendah

1.8-2.59: rendah

2.6-3.39: cukup

3.4-4.12: tinggi

4.2-5.00: sangat tinggi

(3) Interpretasi terhadap kendala e-business bagi UMKM:

$\mathrm{X}<1.85$ : sangat rendah

1.8-2.59: rendah

2.6-3.39: cukup

3.4-4.12: tinggi

4.2-5.00: sangat tinggi

Skor untuk proses adopsi e-business dari para pelaku bisnis UMKM ditampilkan pada Tabel 1 $-3$.

Tabel 1 Pemahaman Layanan Internet

\begin{tabular}{|c|c|}
\hline Pernyataan & Rerata skor \\
\hline $\begin{array}{l}1 \text { Saat ini internet sudah merupakan sebuah sarana } \\
\text { komunikasi utama }\end{array}$ & 4.17105 Adoption \\
\hline $\begin{array}{l}2 \\
\text { Lebih mudah mendapatkan akses data dan } \\
\text { informasi (seperti informasi produk, harga) } \\
\text { menggunakan internet daripada cara tradisional }\end{array}$ & 4.32895 Adoption \\
\hline $\begin{array}{l}3 \text { Lebih mudah berkomunikasi dan berinteraksi } \\
\text { menggunakan internet daripada dengan sa rana } \\
\text { lainnya. }\end{array}$ & 3.88158 Trial \\
\hline $\begin{array}{l}4 \text { Sudah banyak transaksi bisnis yang menggunakan } \\
\text { internet seperti perbankan, reservasi hotel, dan } \\
\text { lainnya. }\end{array}$ & 4.30263 Adoption \\
\hline $\begin{array}{l}5 \text { Terdapat banyak aplikasi dan layanan yang } \\
\text { ditawarkan melalui internet. }\end{array}$ & 4.27632 Adoption \\
\hline $\begin{array}{l}6 \text { E-business sudah menjadi kebutuhan dalam } \\
\text { pemasaran produk perusahaan }\end{array}$ & 4.27632 Adoption \\
\hline Total Skor rata-rata & 4.20614 \\
\hline
\end{tabular}

Sumber: diolah dari data primer (Desember 2012)

Dari tabel 1 di atas, secara umum dapat dilihat bahwa proses adopsi pelaku bisnis UMKM sudah berada dalam tahap adopsi. Total skor rata-rata untuk UMKM sebesar 4.2 menunjukkan bahwa adopsi terhadap inovasi inovasi di dalam pemahaman layanan internet sudah disadari sudah dilakukan sudah dievaluasi dan sudah di adopsi secara menyeluruh. 
Di zaman yang serba cepat dan modern ini, memang sudah tidak perlu diragukan lagi bahwa kekuatan internet dapat menggerakkan segala macam hal terutama bisnis yang dijalankan oleh para pelaku UMKM. Para pelaku UMKM sudah memiliki pemahaman yang komprehensif atau menyeluruh terhadap layanan teknologi informasi e-business dalam rangka membantu proses bisnis usaha yang dijalaninya. Mereka para pelaku bisnis UMKM sudah tidak ragu lagi untuk menggunakan layanan internet dalam menunjang bisnisnya dan dalam rangka untuk meningkatkan profit atau keuntungan bisnis mereka.

Para pelaku bisnis UMKM mempersepsikan bahwa penerapan e-business untuk mendukung system operasional perusahaan sangat bermanfaat secara menyeluruh. Dari mulai pemasaran produk atau jasa mereka, menjaga ketersediaan produk, proses pengadaan bahan baku produk, proses pembuatan sampai dengan proses pendistribusian. Persepsi manfaat E-Business bagi Pelaku Bisnis UMKM dapat dilihat pada Tabel 2.

Tabel 2 Persepsi Manfaat E-Business bagi Pelaku Bisnis UMKM

\begin{tabular}{|r|l|l|l|}
\hline \multicolumn{1}{|c|}{ Pernyataan } & Rerata skor & Intepretasi \\
\hline 1 & $\begin{array}{l}\text { Biaya telekomunikasi berkurang dengan E- } \\
\text { business }\end{array}$ & 4.105263158 & Tinggi \\
\hline 2 & $\begin{array}{l}\text { Biaya distribusi dan penyimpanan produk } \\
\text { berkurang dengan adanya E-business. }\end{array}$ & 4.013157895 & Tingi \\
\hline 3 & $\begin{array}{l}\text { Penyimpanan produk jadi bisa dikendalikan } \\
\text { dengan adanya E-business. }\end{array}$ & 3.907894737 & Tinggi \\
\hline 4 & $\begin{array}{l}\text { Pemasaran produk dapat dilakukan dengan media } \\
\text { yang lebih variatif dan menjangkau masyarakat } \\
\text { yang lebih luas. }\end{array}$ & 4.210526316 & Sangat tinggi \\
\hline 5 & $\begin{array}{l}\text { Jumlah konsumen meningkat dengan adanya E- } \\
\text { business. }\end{array}$ & 4.092105263 & Tinggi \\
\hline 6 & $\begin{array}{l}\text { Harga produk menjadi lebih murah dan profit } \\
\text { menjadi lebih tinggi dengan pemanfaatan E- } \\
\text { Business. }\end{array}$ & 3.881578947 & Tinggi \\
\hline 7 & $\begin{array}{l}\text { Produk yang dijual bisa berasal dari supplier di } \\
\text { seluruh dunia. }\end{array}$ & 3.894736842 & Tinggi \\
\hline 8 & $\begin{array}{l}\text { Pelanggan dan calon pelanggan dapat terjangkau } \\
\text { dalam jumlah besar dan tidak terbatas dengan } \\
\text { adanya E-business. }\end{array}$ & 4.013157895 & Tinggi \\
\hline & Total skor rata-rata & \\
\hline
\end{tabular}

Sumber: diolah dari data primer (Desember 2012)

Total skor rata-rata yaitu 4.02 yang artinya para pelaku bisnis UMKM sangat merasakan manfaat yang diperoleh dengan penggunaan teknologi e-business di dalam proses bisnis perusahaan yang dijalankannya.

Meskipun penerapan e-business dapat mendukung pengembangan pemasaran produk dan jasa pelaku bisnis UMKM, tetapi penerapan e-business tersebut tidak selalu berjalan lancar dan penggunaannya dapat terjadi enam macam kendala seperti yang disajikan dalam Tabel 3 berikut ini berdasarkan persepsi pelaku bisnis UMKM: 


\begin{tabular}{|c|c|}
\hline Fernyataan & Rerata skor \\
\hline $\begin{array}{l}1 \text { Diperlukan waktu lebih untuk menggunakan E- } \\
\text { business. }\end{array}$ & 3.342105263 cukup \\
\hline $\begin{array}{l}2 \text { Diperlukan biaya lebih untuk menggunakan E- } \\
\text { business. }\end{array}$ & 3.236842105 cukup \\
\hline 3 Biaya akses E-business masih mahal. & 3.315789474 cukup \\
\hline 4 Penguasaan teknologi yang masih kurang. & 3.473684211 tinggi \\
\hline $\begin{array}{l}5 \\
\text { Lebih mudah dan aman menggunakan sistem } \\
\text { tradisional dalam pemasaran produk. }\end{array}$ & 2.986842105 cukup \\
\hline $\begin{array}{l}6 \text { Kesulitan dalam monitoring pembayaran } \\
\text { transaksi. }\end{array}$ & 3.131578947 cukup \\
\hline Total skor rata-rata & 3.247807018 \\
\hline
\end{tabular}

Sumber: diolah dari data primer (desember 2012)

Berdasarkan Tabel 3, terdapat persepsi cukup terhadap enam jenis kendala dalam penerapan ebusiness (total rata-rata skor 3.25). Meskipun mereka mempunyai persepsi yang cukup baik terhadap manfaat e-business, tetapi kendalanya juga cukup tinggi.

Para pelaku bisnis UMKM mempersepsikan kendala yang masih ada yaitu misalnya kesulitan dalam proses monitoring pembayaran transaksi, biaya akses internet yang masih cukup relative mahal dan waktu serta usaha lebih untuk memahami teknologi e-business untuk para pemula pelaku bisnis UMKM untuk menerapkan e-business.

\section{PENUTUP}

Kesimpulan dan saran diambil berdasarkan analisis hasil pemeringkatan dan dapat dihasilkan rekomendasi strategik untuk pengembangan e-business pada suatu wilayah.

Dari analisis dan pembahasan diatas dapat disimpulkan bahwa: (1) Sebagian besar entrepreneur sudah memulai usaha sendiri ketika berusia di bawah 35 tahun (60\% dari total responden 76); (2) Sebagian besar entrepreneur adalah wanita dengan alasan menjadi entrepreneur karena kebebasan waktu yang dimiliki sebesar 58\%; (3) Untuk tingkat UMKM, 50\% dari total responden berpendidikan SLTA atau sederajat; (4) 76\% responden sudah menggunakan internet dalam usahanya namun masih belum secara maksimal karena rata-rata masih belum mempunyai website sebagai wadah promosi maupun kegiatan jual beli; (5) proses adopsi pelaku bisnis UMKM sudah berada dalam tahap adopsi. Total skor rata-rata untuk UMKM sebesar 4.2 menunjukkan bahwa adopsi terhadap inovasi inovasi di dalam pemahaman layanan internet sudah disadari sudah dilakukan sudah dievaluasi dan sudah di adopsi secara menyeluruh; (6) manfaat yang diperoleh dengan penggunaan teknologi e-business di dalam proses bisnis perusahaan yang dijalankannya dalam tahap kesadaran dan manfaatnya dapat dirasakan (skor 4.02); (7) persepsi yang cukup baik terhadap manfaat e-business, tetapi kendalanya juga cukup tinggi. 
Sedangkan saran untuk pengembangan kedepan adalah: (1) penyebaran kuesioner yang lebih luas ke pelosok Indonesia agar terwakili semua data yang ada; (2) perluasan cakupan bidang usaha yang disurvei untuk mendapatkan data bidang usaha apa yang paling banyak digeluti oleh entrepreneur saat ini.

\section{DAFTAR PUSTAKA}

Alter, Steven. (2002). Information Systems. New Jersey: Prentice Hall.

Bentahar, Y., \& Namaci, L. (2012). Identifying factors for the successful adoption of e-business by SMEs in developing economies: the case of SMEs in Morocco. World Conference Proceedings, 1 - 14. Washington: ICSB (International Council for Small Business).

Deise, Martin V., Nowikow, C., King, P., dan Wright, A. (2000). Executive's Guide to E-Business: From Tactics to Strategy. New Jersey: John Wiley \& Sons.

Magnusson, Monika. (2011). E-business model design and evaluation: the pieces make the puzzle. European Conference on Information Management and Evaluation, 303-XII. 